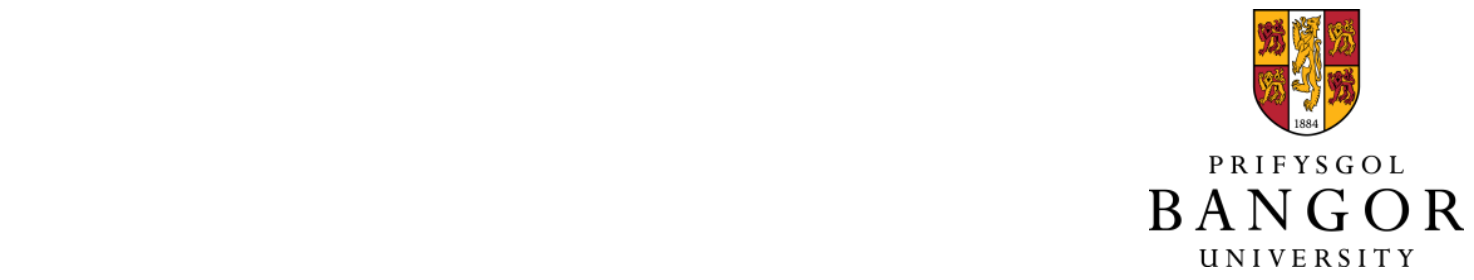

The moderating role of national cultural values in smoking cessation

Hassan, L.M.; Shiu, E.M.

Journal of Business Research

DOI:

10.1016/j.jbusres.2015.03.017

Published: 20/03/2015

Peer reviewed version

Cyswllt i'r cyhoeddiad / Link to publication

Dyfyniad o'r fersiwn a gyhoeddwyd / Citation for published version (APA):

Hassan, L. M., \& Shiu, E. M. (2015). The moderating role of national cultural values in smoking cessation. Journal of Business Research, 68(10), 2173-2180.

https://doi.org/10.1016/j.jbusres.2015.03.017

Hawliau Cyffredinol / General rights

Copyright and moral rights for the publications made accessible in the public portal are retained by the authors and/or other copyright owners and it is a condition of accessing publications that users recognise and abide by the legal requirements associated with these rights.

- Users may download and print one copy of any publication from the public portal for the purpose of private study or research.

- You may not further distribute the material or use it for any profit-making activity or commercial gain

- You may freely distribute the URL identifying the publication in the public portal ?

Take down policy

If you believe that this document breaches copyright please contact us providing details, and we will remove access to the work immediately and investigate your claim. 


\title{
The moderating role of national cultural values in smoking cessation
}

\author{
Louise M. Hassan, Bangor University \\ Edward Shiu, Bangor University
}

February 2015

The authors acknowledge the support of the European Commission in part funding the data collection exercise.

Send correspondence to Louise M. Hassan, Bangor Business School, Hen Goleg, College Road, Bangor University, Bangor, Wales, LL57 2DG, UK, Phone: +44-1248-38-3280, Email: 1.hassan@bangor.ac.uk; Edward Shiu, Bangor Business School, Hen Goleg, College Road, Bangor University, Bangor, Wales, LL57 2DG, UK, Phone: +44-1248-38-2161, Email: e.shiu@bangor.ac.uk. 


\title{
The moderating role of national cultural values in smoking cessation
}

\begin{abstract}
Psychological ownership is an under researched concept in marketing and compulsive consumption. Research in marketing treats psychological ownership as a uni-dimensional construct yet the concept of psychological ownership is more complex. This research draws on the psychological ownership dimensions of self-efficacy and self-accountability to examine how these dimensions jointly explain smokers' quit intentions. A separate contribution lies in understanding the role of culture in smoking cessation. The authors use data across 25 European countries to examine the moderating influence of cultural value dimensions (autonomy/embeddedness, egalitarianism/hierarchy, harmony/mastery) on the relationship between the psychological ownership dimensions and quit intentions. Findings from this research show that psychological ownership plays a more important role in facilitating smoking cessation for smokers in autonomy, egalitarian, and harmony cultures. Given that culture explains crosscountry variation in the psychological process of smoking cessation, national policy makers need to take culture into account when devising tobacco control policies.
\end{abstract}

Keywords: smoking cessation; Europe; culture; Schwartz' cultural value framework; psychological ownership; multilevel modeling 


\section{The moderating role of national cultural values in smoking cessation}

\section{Introduction}

Data from epidemiologists show that smokers on average live 10 years less than non-smokers (Doll, Peto, Boreham, \& Sutherland, 2004). Smoking is the cause of around 30 per cent of all cancer deaths in developed countries (Peto, Lopez, Boreham, Thun, \& Heath Jr., 2006). Given the medical implications of smoking, national governments, the European Commission (EC) and health organizations such as the World Health Organization (WHO) are continuing efforts to combat the harm caused by smoking. Many of these efforts focus on demand reduction and target changing smoking beliefs and behaviors. For example, antitobacco campaigns often target individuals' perceptions about tobacco companies (e.g., the truth ${ }^{\circledR}$ campaign) or the benefits of cessation (e.g., Help - For a life without tobacco campaign).

The majority of research published in the marketing literature has examined beliefs and behaviors regarding the efficacy of antitobacco advertising (e.g., Pechman, Zhao, Goldberg, \& Reibling, 2003) or the influence of tobacco-related policy changes (e.g., Shiu, Hassan, \& Walsh, 2009). However, given that effective tobacco control interventions often require intergovernmental cooperation with shared legislative agendas (e.g., WHO Framework Convention on Tobacco Control: FCTC), understanding the national cultural context is important for policy makers. Research shows that national cultural contexts influence tobacco use (Unger, Cruz, Shakib, Mock, Shields, Baezconde-Garbanati, Palmer, Cruz, Edsall, Gritz, Glynn, \& Johnson, 2003). Yet research exploring the impact of the cultural context on smoking beliefs and behavior is very limited (e.g., Reardon, Miller, Foubert, Vida, \& Rybina, 2006; Walsh, Shiu, \& Hassan, 2014) and focuses mainly on understanding responses to antitobacco advertising. To overcome the limitations of prior research the current research takes a broader view of understanding 
factors that influence consumer motivation to counter compulsive/additive behavior. The current research makes two contributions to extant literature. First, this study provides an examination of the role of psychological ownership in compulsive consumption which is currently absent from the literature. Second, this study also seeks to understanding the influence of Schwartz' (2006) cultural value dimensions on the relationship between a multi-dimensional representation of psychological ownership and quit intentions. Despite a strong theoretical basis the use of Schwartz' cultural value framework is limited in marketing (e.g., Ng, Lee, \& Soutar, 2007). The current research provides an assessment of the worth of this cultural value theory.

\section{Literature review and hypothesis development}

Pierce, Kostova, and Dirks $(2001,2003)$ propose the concept and theory of psychological ownership in organizations, with much subsequent research centered on organizational behavior (e.g., Avey, Avolio, Crossley, \& Luthans, 2009). Pierce, Kostova, and Dirks (2003, p. 86) define psychological ownership as "the state in which individuals feel as though the target of ownership or a piece of that target is theirs (i.e., It is mine!)". Perceiving something as mine is powerful and important in shaping and controlling one's thoughts and behaviors (Pierce, Kostova, \& Dirks, 2001). Psychological ownership applies to connections between individuals and tangible or intangible targets (Dittmar, 1992). The target of psychological ownership is broad and can encompass physical objects (such as an automobile, a building) and abstract concepts (such as an idea, a problem, a decision). With psychological ownership, the target is felt as an extension of the self with individuals feeling obligated to expend energy in caring for and attending to the needs of the target (Belk, 1988). 
In consumer research, the target of psychological ownership mainly centers on possessions with a focus on two overlapping areas. First, exploring the relationship between haptic cues and psychological ownership, studies find that sensory feedback through touch increases psychological ownership (Peck \& Shu, 2009; Peck, Barger, \& Webb, 2013). The second major research area finds support that psychological ownership is one underlying mechanism for the endowment effect. Specifically, the price consumers are willing to pay for a product is significantly less than the price that the consumer will accept to forfeit the product they perceive to own (Shu \& Peck, 2011; Dommer \& Swaminathan, 2013).

Research mostly treats the concept of psychological ownership as a uni-dimensional construct (e.g., Kamleitner \& Erki, 2013; Shu \& Peck, 2011). However, support for a multi-dimensional view comes from Pierce et al. (2003) in their discussions on facets of psychological ownership. Taking this discussion forward, Avey et al. (2009) empirically evidence five underlying dimensions of psychological ownership (territoriality, self-efficacy, accountability, sense of belongingness, and self-identity) in a worker performance context. According to Avey et al. (2009), territoriality is a preventative or defensive form of psychological ownership whereby individuals mark and protect the target of ownership as belonging exclusively to themselves in response to threats of infringement from external entities. Self-efficacy is people's belief in their ability to successfully complete tasks and achieve goals (Bandura, 1977). This psychological ownership component relates to one's need for effectance and speaks to an individual's sense of "I need to do this task, I can do it, and I therefore own the responsibility for achieving success" (Avey et al., 2009, p. 177). Accountability relates to Pierce et al.'s (2003) concept of stewardship, self-sacrifice, responsibility and self-accountability. In this way, feelings that the target of ownership is an extension of the self will coexist with an expectation to hold one's self 
as accountable for the well-being and success or failure regarding the target. Belongingness relates more to the organizational context where social and socio-emotional needs are met by having a place where workers belong to and can call their own within their organization. Lastly, self-identity is the categorization of the self into a role and the incorporation into the self of the meanings, significance and expectations associated with that role. When the self is integrated with the target of psychological ownership, behavior addressing the needs of the target is deemed as an expression of the self transforming the frame of reference from "what will I gain from this effort" to "this effort is an expression of who I am" (Avey et al., 2009, p.179). In the context of the current research, the authors' aim is in gaining a better understanding of key factors on persuading smokers to quit through cross-national antismoking campaigns. Research (e.g., Durkin, Brennan, \& Wakefield, 2012) shows that past antismoking campaigns focus mainly on boosting smokers' self-efficacy as well as getting smokers to acknowledge and be accountable for the harm caused by smoking. Thus, the current cross-country research takes a first step in examining the differential roles of two factors, namely self-efficacy and self-accountability, as dimensions of psychological ownership in explaining variance in quit intentions by smokers across Europe.

\subsection{The individual (level-1) model}

Fig.1 shows the individual (level-1) model embedded within a cross-cultural framework. Specifically, self-efficacy (Bandura, 1977) is the self-judgment of one's operative capabilities regarding successful enactment and successful accomplishment of the target task (e.g., quitting smoking). Such self-judgment functions as a proximal determinant of thoughts, feelings and action tendency regarding the target task. Extant research shows self-efficacy to be a potent force in tackling addiction. A recent review confirms the relevance of self-efficacy as an "important 
predictor of outcome, or as a mediator of treatment effects" in treating substance abuse (Kadden \& Litt, 2011, p. 1120). Research further shows the influence of self-efficacy on behavioral intentions varies across national samples (Vassallo, Saba, Arvola, Dean, Messina, Winkelmann, Claupein, Lahteenmaki, \& Shepherd, 2009). Nevertheless, Hosking, Borland, Yong, Fong, Zanna, Laux, Thrasher, Lee, Sirirassamee, and Omar, (2009) find self-efficacy to have a significant impact on quit intentions across samples covering six countries. Thus, H1. Smokers with higher levels of self-efficacy will have greater quit intentions.

In the public health literature, individuals are firmly cast as responsible for their own health and for the health of others (Peterson, 1997). Individuals need to be proactive in making themselves aware of potential health risks and to act in accordance with advice from public health bodies (Greco, 1993). With decades of antitobacco campaigns and policy actions by national and supra-national organizations (e.g., WHO), being a smoker is subject to blame for a failure in taking care of the self and a failure in living up to socially constructed self-standards (Peterson, 1997).

Pierce et al. (2003) assert that being self accountable for a target comes with the feelings of ownership. Perceptions and expectations of holding one's self accountable have implications for motivations and actions regarding the self. The investment of an individual's self into the target of psychological ownership (e.g., my problem) leads to stronger motivation and more willingness to self-sacrifice in attending to and addressing the needs of the target (Pierce et al., 2003; Avey et al., 2009). Further, Peloza, White, and Shang (2013, p. 105) define selfaccountability as the "activation of a person's desire to live up to internal self-standards". These authors find self-accountability leads to more positive response (such as purchase intention) to 
ethical appeals. Further, Passyn and Sujan (2006) find self-accountability to impact behavioral intentions to use sunscreen and in the context of antismoking intervention, Grogan, Flett, ClarkCarter, Gough, Davey, Richardson, and Rajaratnam (2011) find (self-) accountability to influence quit intentions. Thus,

H2. Smokers with higher levels of self-accountability will have greater quit intentions.

Figure 1 here

\subsection{National cultural frameworks}

How people across the world think, feel and act in response to issues they encounter in daily life is structured in accordance to their social environments (e.g., family, community, work place, social and political systems). People are programmed as they grow up and gather life experiences as they interact with their social environments. Thus, Hofstede (1980, p.25) defines culture as "the collective programming of the mind which distinguishes the members of one human group from another". Research shows national culture to influence behavior acting as a moderator of individual-level relationships (e.g., Steenkamp \& Geyskens, 2006). Extant literature shows one dominant cultural framework, that of Hofstede $(1980,2001)$ with much less research attention on Schwartz' (2006) framework. The lack of attention to Schwartz is surprising given observations that find Schwartz' framework to be superior to Hofstede's regarding coverage and theoretical foundations (Engelen \& Brettel, 2011; Steenkamp, 2001) as well as the ability to offer greater explanatory power ( $\mathrm{Ng}$ et al., 2007).

\subsubsection{Schwartz' cultural framework}

Schwartz (2006) anchors his cultural framework in terms of generic human values and proposes three cultural value dimensions (autonomy/embeddedness, egalitarianism/hierarchy, harmony/mastery) covering seven cultural value orientations (see Fig. 2). The first dimension 
addresses the issue of boundaries between individuals and the group. Cultures that place a high value on autonomy reflect individuals who assert their independent rights, who cultivate and express their own opinions, ideals and talents, and strive for uniqueness. Schwartz distinguishes between two types of autonomy. Intellectual autonomy refers to individuals' freedom to pursue independently their own intellectual inspirations. Cultures with such an orientation consider the values of creativity, curiosity and broadmindedness to be important. Affective autonomy is a cultural orientation where the values of pleasure, excitement and variety are taken as important life values, where individuals are encouraged to engage in positive experience for personal gratification. The autonomy and embeddedness orientations form polar opposites in the higher cultural dimension of autonomy/embeddedness. Embeddedness emphasizes belongingness to the group and a life pursuing shared goals. People in embedded cultures tend to find meaning through social relationships and place a high importance on respect for tradition, security and obedience. These individuals find expression in values favoring propriety and harmony in interpersonal and other social relations.

The second cultural value dimension concerns the preservation of the social fabric with individuals behaving in a responsible way to ensure a social good. This dimension comprises the value orientations of egalitarianism and hierarchy. Specifically, egalitarianism advocates that individuals in a society should be treated equally which stems from the commitment for collective well-being. Values of high importance within egalitarian cultures are equality, social justice and honesty that jointly exhort voluntary commitment to promoting the welfare of others. The polar opposite of egalitarianism is hierarchy which reflects a culture with recognized roles and an unequal distribution of power and responsibilities among individuals. Values such as social power, authority and wealth are of prime importance to hierarchically oriented cultures. 
People in hierarchical cultures are more inclined to act to preserve the welfare of the in-group with little concern for voluntary pro-social actions.

The final dimension considers how individuals negotiate relations in both the natural and social world. The harmony orientation emphasizes the status quo, leaving the world unchanged and trying to understand the essential state of the world. Thus, values such as unity with nature and a world at peace are central to this orientation. This orientation is also conceptualized as a culture that fosters non-assertiveness in social relations, engendering peace and unity with social others as well as with the natural world. The opposing orientation to harmony is mastery. Values important to people in cultures that emphasizes mastery include ambition, success and competence. These values place an emphasis on mastery of the natural and social environments. People in mastery cultures are encouraged to attain personal goals through self-assertion. The seven value orientations comprising these three bipolar dimensions form a circumplex as depicted in Fig. 2 where value orientations closer to each other are compatible while those opposing each other are incompatible (Schwartz, 2006). Fig. 1 details the cross-cultural conceptual model showing the cross-level moderating effects relating to the discussions below.

Figure 2 here

\subsubsection{The moderating effect of autonomy/embeddedness}

Individuals in autonomy cultures view themselves as autonomous entities who are free to independently express their own preferences, ideas and abilities (Schwartz, 2006). For smokers in autonomy cultures, if they feel that they can successfully quit smoking, they would see fewer barriers to successfully give up smoking and thus be more motivated to quit. Hence, for these smokers the effect of self-efficacy on quit intentions will be stronger. Intellectual autonomy shares with egalitarianism the cultural view that individuals take voluntary action in response to 
perceived individual rights and responsibilities (Schwartz, 2006). Thus, given their inclination to act freely in accordance to their personal ideas and understanding of situations, smokers in autonomy cultures will have stronger quit intentions if they feel they are responsible (i.e. selfaccountable) for the harms caused by smoking.

On the other hand, people in embedded cultures perceive themselves to be part of (or embedded in) the collective where their social role and obligations take precedence over their individual goals and aspirations. They value the maintenance of the status quo and find meaning through social relationships by identifying with in-groups. Research shows that smokers identify themselves and find comfort as members of an in-group with other smokers (Hamilton \& Hassan, 2010). As such, they are loyal to their in-group (fellow smokers) and reluctant to take action that would disturb in-group solidarity (Schwartz, 2006). Thus, the effect of self-efficacy on intention is weaker because motivations to quit by smokers in embedded countries are lower even if they believe they have the ability to do so. Consistent with the above argument, the same reason applies whereby the reluctance to take action that might disrupt in-group solidarity and the status quo will also result in a weaker self-accountability-intention relationship among smokers in embedded cultures. Thus,

H3a. The relationship between self-efficacy and quit intentions is stronger for smokers in autonomy cultures, however the relationship is weaker in embedded cultures.

H3b. The relationship between self-accountability and quit intentions is stronger for smokers in autonomy cultures, however the relationship is weaker in embedded cultures.

\subsubsection{The moderating effect of egalitarianism/hierarchy}


Equality is at the heart of the society that places an emphasis on egalitarianism (Schwartz, 1994). People in egalitarian cultures regard each other as equals and are motivated to cooperate and act for the benefit of the welfare of society. Therefore, if smokers believe they have the ability to quit, those in egalitarian cultures will have a stronger impetus to do so. The reason is because they believe that citizens are equals and thus have the power, control and ability to enact changes that are beneficial to the common good (quitting smoking dramatically reduces the health and economic burden of tobacco use, CDC, 2010). Further, in egalitarian cultures, a sense of individual responsibility is essential for collective well-being where equality equates to the sharing of responsibility among and across citizens (Schwartz, 2006). Responsibility is internalized (i.e. made self-accountable) with individuals free to independently act to attend to the needs of the target over which they have assumed responsibility. Thus, if smokers feel that they are accountable to themselves for the harm attributed to their smoking, then in an egalitarian culture they will perceive greater responsibility and greater motivation to enact voluntary changes to their behavior.

Unlike egalitarian cultures, hierarchical cultures reflect social pressure on individuals to obey the views of others who are held in a higher status (Schwartz, 2006). With unequal distribution of power in hierarchical cultures, people in such countries would be reluctant to enact changes even if they believe that they have the ability to do so. The reason is that they are constrained by social conventions whereby the power to enact change lies with others of a higher status (such as doctors and legislators). Further, people in hierarchical cultures are socialized to fulfilling their obligations in accordance to their socially prescribed roles. Thus, they view their roles and obligations as more serving those in higher authority than serving themselves (Schwartz, 2006). Therefore, the cultural influence of hierarchy dampens the impetus to act even 
though individuals feel a personal responsibility to address the self-harm attributed to smoking. Thus,

H4a. The relationship between self-efficacy and quit intentions is stronger for smokers in egalitarian cultures, however the relationship is weaker in hierarchical cultures.

H4b. The relationship between self-accountability and quit intentions is stronger for smokers in egalitarian cultures, however the relationship is weaker in hierarchical cultures.

\subsubsection{The moderating effect of harmony/mastery}

According to Schwartz (2006), harmony reflects a desire to fit into the social environment. Thus, for people in harmony cultures, their motivation to act on circumstances in a manner consistent with acceptable norms and shared social values is stronger. Given the long established tobacco control policies (e.g., WHO FCTC) and repeated antitobacco campaigns undertaken across Europe (e.g., HELP - for a life without tobacco), citizens across the European Union Member States generally perceive smoking as a socially harmful behavior. Therefore in sympathy with the values portrayed by their society, smokers in harmony cultures have greater motivation to quit if they believe they have the ability to do so. In a similar manner, given their preference and motivation to uphold social values, smokers in harmony cultures will be more likely to act on their responsibilities and be more motivated to quit if they feel they are accountable to themselves regarding the harm from smoking.

However, according to Schwartz (2006), the cultural dimension of harmony/mastery relates closely to that of egalitarianism/hierarchy, thus one might expect a similar moderating influence to be found across these two cultural dimensions. In particular, both hierarchy and mastery orientations emphasize the differential distribution of power and resources in intergroup 
competitions, whereas egalitarian and harmony orientations emphasize cooperative regulation of intergroup and other social relations. Yet, Schwartz (2006) notes that the harmony/mastery dimension relates only weakly with individuals' attitudes and behaviors. On balance, given the previous arguments on the dampening effects of the hierarchy orientation and the boosting effects of harmony, the moderating effects of the harmony/mastery dimension on the relationships between intentions and its antecedents, the present research posits the following: H5a. The relationship between self-efficacy and quit intentions is stronger for smokers in harmony cultures, however the relationship is weaker in mastery cultures.

H5b. The relationship between self-accountability and quit intentions is stronger for smokers in harmony cultures, however the relationship is weaker in mastery cultures.

\section{Method}

\subsection{Participants and procedure}

Visitors to an EC website participated in the survey and data from smokers residing in the European Union (EU) was collected between 2006 and 2008. Participants were directed to the online survey by clicking on a web link advertising the survey. Respondents to the online survey completed questions on the model variables as well as demographic information. A total of 3,155 responses from 25 participating EU countries were included with average sample size equal 126 (minimum $=4$ for Ireland and maximum $=398$ for Greece). The mean age of this total sample is 35.4 years (lowest mean age $=25$ in Lithuania and highest mean age $=44$ in the Netherlands), with the overall sample nearly equally split across gender at $49 \%$ females (minimum $18 \%$ females in Cyprus and maximum $72 \%$ females in the Netherlands). In total the survey took around 10 minutes to complete. Participants were free to withdraw at any time and were not 
required to complete each question. The questionnaire was developed in English and translated into the 22 EU national languages by official EC translators following standard EC procedures.

\subsection{Measures}

\subsubsection{Level-1 model}

Two items assess self-efficacy to quit smoking in the next three months. In line with Dabholkar and Bagozzi (2002), these two items capture the participants' confidence in being able to stop smoking within the next three months (7-point scale from 0 "not confident at all" to 6 "very confident") and their assessment of the probability that they can stop smoking within the next three months (7-point scale from 0 "very low" to 6 "very high"). The two items possess acceptable internal consistency across the 25 country samples (minimum alpha $=.62$, maximum alpha $=.99$, mean alpha $=.90)$. In line with Passyn and Sujan $(2006)$, three items assess selfaccountability with a 7-point ( 0 "Not at all" to 6 "Very much") rating scale in response to the questions: "How accountable would you feel if you were to find that you have been harmed by the effects of smoking?" "How accountable are you in protecting yourself from the harmful effects of smoking?" and "How strongly do you feel that it is your responsibility to protect yourself from the harmful effects of smoking?" The three items yield alpha from a minimum of .58 to a maximum of .93 (average alpha across country samples $=.78$ ). Lastly, three items assess behavioral intention using a 7-point ( 0 "definitely do not" to 6 "definitely do") rating scale in response to the questions: "You intend/plan/want to stop smoking within the next three months". The three items $($ minimum alpha $=.58$, maximum alpha $=.99$, mean alpha $=.85)$ were averaged to form a composite measure of intention, as were the self-efficacy items and the selfaccountability items.

\subsubsection{National cultural values}


Cultural dimensions were calculated from round 3 and round 4 of the European Social Survey (ESS, 2006; 2008) where data was collected from all 25 countries that participated in at least one round of the ESS. Country-level value measures were calculated based on the four-step procedure documented in Schwartz (2006). Higher values represent a country with a stronger emphasis on autonomy, egalitarianism and harmony. Davidov, Schmidt, and Schwartz (2008) evidence configural and metric equivalence of the ESS measures.

The appropriateness of aggregating each of the seven individual-level cultural orientations to the country level was determined via ANOVA (null model) by assessing if cross-country variations were evident (see Bliese, 2000). The ANOVA result reveals significant variations in the mean level of each of the value orientations across the 25 countries $(p<.001)$ with moderate values of intraclass correlation ICC1 (mean value $=.08$, range $=.05-.13$ ) and consistently high values for ICC2 $($ minimum $=.99)$. ICC1 represents the proportion of the total variance attributable to group (country) membership. ICC2 provides an estimate of the reliability of the group (country) means. The ICC2 values far exceed the threshold (> .6) attesting to the reliability of the country-level value orientations adopted in this study. Lastly, an examination of interrater agreement $(r \mathrm{WG})$ for these value orientations is pertinent to justify aggregation of the (within country) individual responses to the country level. The $r_{\mathrm{WG}}$ calculations yield results well above the .14 threshold recommended by Smith-Crowe, Burke, Cohen, and Doveh (2014), for harmony $($ mean $=.66 ;$ range $.53-.76)$, for egalitarianism $($ mean $=.87$; range $.79-.93)$, for intellectual autonomy $($ mean $=.80 ;$ range $.68-.88)$, for affective autonomy $($ mean $=.67$; range $.56-.80)$, for mastery $($ mean $=.66$; range $.52-.74)$, for hierarchy $($ mean $=.60$; range $.40-.70)$, and for embeddedness $($ mean $=.85$; range $.70-.93)$. Overall, these results provide evidence in support of aggregating the value orientations to the country level. 


\subsection{Data analysis overview and assessment of measurement invariance}

Hierarchical linear modeling (HLM) was employed to assess the conceptual model based on the computer package HLM 6.06. Multilevel analysis is the preferred method where regression is conducted simultaneously at the individual and group (country) levels. Following recommended procedures (e.g., Raudenbush \& Bryk, 2002; Hofmann, 1997) level-1 (individual-level) variables were group-mean centered and level-2 (country-level) variables were grand-mean centered. To fully examine possible country-level effects, a sequence of HLM models must be examined. Specifically, a null model was specified to assess between-country variation in intentions followed by a random-coefficient model to assess the level-1 model and variations in the intercept and slopes, and finally a slopes-as-outcomes model to test the hypothesized moderating effects. The influences of the cultural dimensions were examined separately because of the degree of observed correlations between the cultural dimensions.

Prior to the main HLM analyses measurement invariance is established up to the level of metric invariance for each of the level-1 measures. Metric invariance assesses if the first-order factor loadings are equal across country samples. Achieving metric invariance ensures that the scores on the measurement items can be meaningfully compared across countries. The results support full metric invariance $(\Delta \chi 2(24)=28.90, p=.224)$ across all 25 country samples for the self-efficacy construct, partial metric invariance $(\Delta \chi 2(17)=25.21, p=.090)$ across 20 countries (excluding Hungary, Ireland, Poland, Sweden, and Romania) for the self-accountability construct, and partial metric invariance $(\Delta \chi 2(19)=27.80, p=.087)$ across 21 countries (excluding Denmark, Ireland, Luxembourg and Romania) for the intention construct. A robustness check was conducted based on seventeen country samples with sample sizes greater than 30 (excluding samples from Cyprus, Denmark, Ireland, Luxemburg, Romania, Slovakia, 
Sweden, and the United Kingdom). The results of the robustness check fully support the conclusions reported for the total sample. Together, these results provide evidence that the scales are suitable for cross-country examination.

\section{Results}

\subsection{Preliminary examination of null and random-coefficient models}

The analysis of the null model yielded results showing significant between-country variance $\left(\chi^{2}(22)=132.51, p<.001\right)$ indicating that the intercept term $\left(\beta_{0 \mathrm{j}}\right)$ vary across the 25 countries. The ICC1 applies only to random-intercept models and as such ICC1 does not provide indications on variations in slope values across the countries. Thus, this information is only of marginal interest given the cross-level moderating hypotheses. The design effect (DE) was also determined where DE is a measure that adjusts the ICC1 for average class size. If the DE value is over 2, then HLM analysis is appropriate as the assumption of independent observations is violated (Muthen \& Satorra, 1995). The ICC1 for this study is .042 with corresponding DE value of 6.31 and given these results, HLM was used to explore between-country effects.

Next a random-coefficient model was specified where the individual-level model is examined. These results show that self-efficacy $(B=.26, t=8.99, p<.001)$ and selfaccountability $(B=.32, t=7.92, p<.001)$ each have a significant impact on quit intentions. Examination of the variance components shows significant variation across the $25 \mathrm{EU}$ countries for the self-efficacy-intention slope (variance component $=.02, \chi^{2}(24)=127.45, p<.001$ ) and the self-accountability-intention slope (variance component $\left.=.03, \chi^{2}(24)=109.92, p<.001\right)$. Calculation for $\mathrm{R}^{2}$ for the level-1 model in accordance with Hofmann, Griffin, and Gavin (2000) shows that just under $40 \%$ of the variation in quit intentions can be explained by the two 
psychological ownership variables. Finally, examination of the variation in intercept $\left(\beta_{0 \mathrm{j}}\right)$, that is mean intention level across the 25 EU countries, shows that significant cross-country variation exists (variance component $\left.=.12, \chi^{2}(24)=218.80, p<.001\right)$.

\subsection{Testing the impact of culture (slope-as outcome models)}

In each analysis, as recommended by Raudenbush and Bryk (2002), whenever a Schwartz value dimension was entered to explain the slope effect, the dimension was also entered into the model to explain between-country variation in the intercept. Furthermore, given a high correlation $(>.7)$ between the Schwartz dimensions of harmony/mastery and egalitarianism/hierarchy results are reported separately for each dimension. The results (see Table 1) support five of the cross-level hypotheses, but not H5b. The proportion of variance explained in the self-efficacy-intention slope and in the self-accountability-intention slope was estimated by comparing the variance estimates from the intercept-as-outcome model as a base against that from the slope-as-outcome model. The results show that the slope-as-outcome model accounts for at least modest amounts (from 9\% to $23 \%$, see Table 1) of between-country variations.

Given that eight countries (Cyprus, Denmark, Ireland, Luxembourg, Slovakia, Sweden, United Kingdom, and Romania) have sample sizes under 30, a robustness check was undertaken with the remaining seventeen country samples. The robustness check shows that the multilevel model results as reported in Table 1 remain mostly unchanged with the exception of one moderating effect (harmony/mastery $\times$ self-efficacy) being significant at the $20 \%$ level $(p<.20$ two tailed) rather than at the $10 \%$ level. The robustness check is acceptable given Mathieu, Aguinis, Culpepper, and Chen's (2012) observation on the severe limitations regarding statistical 
power in detecting cross-level interactions. Mathieu et al. (2012) further argue that in the absence of a strong and well established research base, a threshold of .20 is acceptable.

Table 1 here

\subsection{Follow-up simple slopes analysis}

In order to assess the moderating relationships fully, follow-up simple slopes analyses based on Preacher, Curran, and Bauer's (2006) computational tool were conducted for the five significant moderating effects found. Figure 3 shows the five interaction plots arising from the simple slopes analyses. The results show that the effect of self-efficacy on intention is significantly positive $(p<.01)$ regardless of the cultural value orientation. The results also show the effect (i.e. slope) is stronger in countries closer to the autonomy pole, the egalitarian pole or the harmony pole. The effect of self-accountability on intention is also significant across all regions of the egalitarianism/hierarchy dimension with stronger effects toward the egalitarianism pole. The results on the differential effects of self-accountability on intention yield a very similar interpretation such that the relationship between self-accountability and intention is stronger for individuals in autonomy or egalitarian cultures. Additionally, the analysis on region of significance for autonomy/embeddedness reveals that for individuals in countries with cultural values very close to the embedded pole (such as Greece, Poland and Slovakia), no significant relationship between self-accountability and quit intentions exists. The simple slopes analyses and associated charts confirm the nature of the hypothesized moderating effects (H3a, H4a, H5a, $\mathrm{H} 3 \mathrm{~b}$, and H4b).

Figure 3 here

\section{Discussion}


The current research provides one of the first examples in examining the usefulness of psychological ownership in countering compulsive/additive behaviors. Further, the research extends literature in two other significant ways. First, by examining a multidimensional view of psychological ownership (through examining self-efficacy and self-accountability) and second, by examining smoking beliefs and behavior through the concept of psychological ownership across cultures. The research confirms the important roles played by both self-efficacy and selfaccountability in bolstering quit intentions across Europe. In particular, the findings evidence the strong explanatory power of the two psychological ownership variables, accounting for a substantial proportion (around 40\%) of the variation in quit intentions. However, policy makers and legislators need to understand the role of the cultural context in facilitating or inhibiting smoking cessation. The findings highlight that cultural value dimensions play an important role in strengthening or dampening individual drivers of quit intentions. In particular, smokers in European countries (e.g., France) that place greater emphasis on autonomy, egalitarian and harmony values have stronger associations between self-efficacy and quit intentions. Similar cultural influences are found on the relationship between self-accountability and quit intentions, though not in the case of harmony values. Greater resistance to programs engendering quitting is likely in European countries (e.g., Lithuania) that emphasize relatively stronger embeddedness, hierarchy and mastery values. This resistance likely accounts for the higher smoking prevalence rates in relatively more embedded cultures (e.g., Poland versus Belgium) and more hierarchical cultures (e.g., Latvia versus Finland).

Many social marketing campaigns target audiences across national borders in order to both utilize campaigns that have been successful and to keep costs under control. Recent examples of transnational marketing communication efforts include Amnesty International's "The Stop 
Violence Against Women (SVAW) campaign", the European Union's "Help - for a life without tobacco" and "Ex-smokers are unstoppable", or the United Nations' "Unite for children, Unite against AIDS" campaign. As a result national health bodies and consumer protection agencies need to pay attention to how culture might impact the effectiveness of campaigns not developed or tested for the target segment/country. One central aspect is that the campaign messages might not suit the audience. Research shows the central role that self-efficacy plays in smokers' acceptance of factual information that induces a sense of vulnerability (Wolburg, 2006). Further, Pechmann, Zhao, Goldberg, and Reibling (2003) identify seven potential successful message themes for antitobacco advertising when targeting adolescents. Of the seven themes, three (marketing tactics, selling disease and death as well as the refusal skills role model) target an increase in self-efficacy. These three themes provide exemplars that would more likely work in countries high in autonomy, egalitarianism and harmony, but the current research shows that boosting self-efficacy might not work effectively in countries high in embeddedness, hierarchy or mastery. The current research also finds that boosting self-accountability does not lead to an increase in quit intentions among smokers in embedded or hierarchical cultures. To overcome the dampening effects of these two cultural influences, antitobacco campaigns in these countries should consider shifting the emphasis on the personal harm caused by smoking to the promotion of a socially agreed view that smoking harms both others through secondhand smoke as well as society through financial and other burdens to the national health system.

The current study evidences the important role of psychological ownership in cross-cultural consumer research. Beyond extending the target of ownership from tangible consumer products to an intangible concept (my addiction, my problem), findings from the cross-country study confirm the view that increasing psychological ownership (higher levels of self-efficacy and self- 
accountability) can lead to greater motivation to act. However, results from past and future studies will need to be considered with regard to the cultural context within which the study is conducted. The current research shows that conflicting findings from research undertaken across the globe can arise and are partially explainable by the cultural context.

The current research is not without limitations that open up new research avenues. First, the sample and conclusions apply to one region in the world (EU Member States) and thus greater cultural similarity exists among these countries. Second, the samples comprise smokers who selfselected to take part in a web survey, thus these respondents may not fully represent the views of smokers within each country. The methodology in the current research has also resulted in the variability of the sample sizes across the countries with some countries having small to modest sample sizes. Third, only one item in the ESS survey captures the harmony/mastery cultural value orientation and thus lacks power. Indeed, Schwartz (2006, p.177) reports that the measurement of the harmony/mastery dimension may be problematic. Schwartz (2006) also report weak correlations of this dimension with social attitudes and behaviors. Fourth, the high correlations between Schwartz' dimensions preclude a simultaneous examination of all three cultural dimensions in the cross-level analyses in order to avoid issues of multicollinearity. Fifth, although the explanatory power of the models are adequate, given that significant cross-country variation still remains to be explained other country-level factors may also have an impact on the level-1 model relationships. Lastly, future consumer research in the area of psychological ownership needs to assess the full dimensional structure of the concept (territoriality, selfefficacy, accountability, sense of belongingness, and self-identity). The current research examining only two dimensions precludes a full understanding of the role of psychological ownership. 


\section{References}

Avey, J.B., Avolio, B.J., Crossley, C.D., \& Luthans, F. (2009). Psychological ownership: Theoretical extensions, measurement and relation to work outcomes. Journal of Organizational Behavior, 30, 173-191.

Bandura, A. (1977). Self-efficacy: toward a unifying theory of behavioral change. Psychological Review, 84, 191-215.

Belk, R.W. (1988). Possessions and the extended self. Journal of Consumer Research, 15, 139168.

Bliese, P.D. (2000). 'Within group agreement, non-independence and reliability: Implications for data and analysis'. In K.J. Klein and S.W.J. Kozlowski (eds), Multilevel Theory, Research, and Methods in Organizations: Foundations, Extension, and New Directions, pp. 355-373. San Francisco, CA: Jossey-Bass.

CDC (2010). Centers for Disease Control and Prevention. Tobacco Control State Highlights, 2010. Atlanta: U.S. Department of Health and Human Services, Centers for Disease Control and Prevention, National Center for Chronic Disease Prevention and Health Promotion, Office on Smoking and Health, 2010.

Dabholkar, P.A., \& Bagozzi, R.P. (2002). An attitudinal model of technology-based self-service: Moderating effects of consumer traits and situational factors. Journal of the Academy of Marketing Science, 30, 184-201.

Davidov, E., Schmidt, P., \& Schwartz, S.H. (2008). Bringing values back in the adequacy of the European Social Survey to measure values in 20 countries. Public Opinion Quarterly, 72, $420-445$. 
Dittmar, H. (1992). The social psychology of material possessions: To have is to be. New York: St. Martin's Press.

Doll, R., Peto, R., Boreham, J., \& Sutherland, I. (2004). Mortality in relation to smoking: 50 years' observations on male British doctors. British Medical Journal, 328, 1519-1527.

Dommer, S.L., \& Swaminathan, V. (2013). Explaining the endowment effect through ownership: The role of identity, gender, and self-threat. Journal of Consumer Research, 39, 1034-1050.

Durkin, S., Brennan, E., \& Wakefield, M. (2012). Mass media campaigns to promote smoking cessation among adults: An integrative review. Tobacco Control, 21, 127-138.

Engelen, A., \& Brettel, M. (2011). Assessing cross-cultural marketing theory and research. Journal of Business Research, 64, 516-523.

ESS (2006). European Social Survey Round 3 Data (2006). Data file edition 3.4. Norwegian Social Science Data Services, Norway - Data Archive and distributor of ESS data.

ESS (2008). European Social Survey Round 4 Data (2008). Data file edition 4.2. Norwegian Social Science Data Services, Norway - Data Archive and distributor of ESS data.

Greco, M. (1993). Psychosomatic subjects and 'the duty to be well': Personal agency within medical rationality. Economy and Society, 22, 357-372.

Grogan, S., Flett, K., Clark-Carter, D., Gough, B., Davey, R., Richardson, D., \& Rajaratnam, G. (2011). Women smokers' experiences of an age-appearance anti-smoking intervention: A qualitative study. British Journal of Health Psychology, 16, 675-689.

Hamilton, K. \& Hassan, L. (2010). Self-concept, emotions and consumer coping: Smoking across Europe. European Journal of Marketing, 44, 1101-1120.

Hofmann, D.A. (1997). An overview of the logic and rationale of hierarchical linear models. Journal of Management, 23, 723-744. 
Hofmann, D.A., Griffin, M.A., \& Gavin, M.B. (2000). The application of hierarchical linear modeling to organizational research. In K.J. Klein \& S.W.J. Kozlowski (eds.), Multilevel theory, research, and methods in organizations: Foundations, extensions, and new directions (pp. 467-511). Jossey-Bass, CA: Wiley.

Hofstede, G. (1980). Culture's Consequences: International Differences in Work-related Values. Beverly Hills, CA: Sage.

Hofstede, G. (2001). Culture's consequences: Comparing values, behaviors, institutions and organizations across nations. Thousand Oaks, CA; Sage.

Hosking, W., Borland, R., Yong, H-H., Fong, G., Zanna, M., Laux, F., Thrasher, J., Lee, W.B., Sirirassamee, B., \& Omar, M. (2009). The effects of smoking norms and attitudes on quitting intentions in Malaysia, Thailand and four Western nations: a cross-cultural comparison. Psychology \& Health, 24, 95-107.

Kadden, R.M., \& Litt, M.D. (2011). The role of self-efficacy in the treatment of substance use disorders. Addictive Behaviors, 36, 1120-1126.

Kamleitner, B., \& Erki, B. (2013). Payment method and perceptions of ownership. Marketing Letters, 24, 57-69.

Mathieu, J.E., Aguinis, H., Culpepper, S.A., \& Chen, G. (2012). Understanding and estimating the power to detect cross-level interaction effects in multilevel modeling. Journal of Applied Psychology, 97, 951-966.

Muthen, B.O., \& Satorra, A. (1995). Complex sample data in structural equation modeling. Sociological Methodology, 25, 267-316.

Ng, S.I., Lee, J.A., \& Soutar, G.N. (2007). Are Hofstede's and Schwartz's value frameworks congruent? International Marketing Review, 24, 164-180. 
Passyn, K., \& Sujan, M. (2006). Self-accountability emotions and fear appeals: Motivating behavior. Journal of Consumer Research, 32, 583-589.

Peck, J., \& Shu, S.B. (2009). The effect of mere touch on perceived ownership. Journal of Consumer Research, 36, 434-447.

Peck, J., Barger, V.A, \& Webb, A. (2013). In search of a surrogate for touch: The effect of haptic imagery on perceived ownership. Journal of Consumer Psychology, 23, 189-196.

Pechmann, C., Zhao, G., Goldberg, M.E., \& Reibling, E.T. (2003). What to convey in antismoking advertisements for adolescents? The use of protection motivation theory to identify effective message themes. Journal of Marketing, 67, 1-18.

Peloza, J., White, K., \& Shang, J. (2013). Good and guilt-free: The role of self-accountability in influencing preferences for products with ethical attributes. Journal of Marketing, 77, 104119.

Peterson, A. (1997). Risk, governance and the new public health. In A. Peterson, \& R. Bunton, (eds). Foucault, Health and Medicine (pp. 189-206). London: Routledge.

Peto, R., Lopez, A., Boreham, J., Thun, M., \& Heath Jr, C. (2006). Mortality from smoking in developed countries 1950-2000. (2nd ed.) Oxford: University Press.

Pierce, J.L., Kostova, T., \& Dirks, K.T. (2001). Toward a theory of psychological ownership in organizations. Academy of Management Review, 26, 298-310.

Pierce, J.L., Kostova, T., \& Dirks, K.T. (2003). The state of psychological ownership: integrating and extending a century of research. Review of General Psychology, 7, 84-107.

Preacher, K.J., Curran, P.J., \& Bauer, D.J. (2006). Computational tools for probing interaction effects in multiple linear regression, multilevel modeling, and latent curve analysis. Journal of Educational and Behavioral Statistics, 31, 437-448. 
Raudenbush, S.W., \& Bryk, A.S. (2002). Hierarchical linear models: Applications and data analysis methods. Newbury Park, CA: Sage.

Reardon, J., Miller, C., Foubert, B., Vida, I., \& Rybina, L. (2006). Antismoking messages for the international teenage segment: The effectiveness of message valence and intensity across different cultures. Journal of International Marketing, 14, 115-138.

Schwartz, S.H. (1994). Beyond individualism/collectivism: New cultural dimensions of values. In U. Kim, H.C. Triandis, C. Kagitcibasi, S-C. Choi, \& G. Yoon (eds.), Individualism and collectivism: Theory, method and application (pp. 85-119). Newbury Park, CA: Sage.

Schwartz, S.H. (2006). A theory of cultural value orientations: explication and applications. Comparative Sociology, 5, 137-182.

Shiu, E., Hassan, L.M., \& Walsh, G. (2009). Demarketing tobacco through governmental policies - The 4Ps revisited. Journal of Business Research, 62, 269-278.

Shu, S.B., \& Peck, J. (2011). Psychological ownership and affective reaction: Emotional attachment process variables and the endowment effect. Journal of Consumer Psychology, 21, $439-452$.

Smith-Crowe, K., Burke, M.J., Cohen, A., \& Doveh, E. (2014). Statistical significance criteria for the rwg and average deviation interrater agreement indices, Journal of Applied Psychology, 99, 239-261.

Steenkamp, J-B.E.M., \& Geyskens, I. (2006). How country characteristics affect the perceived value of web sites. Journal of Marketing, 70, 136-150.

Steenkamp, J-B.E.M. (2001). The role of national culture in international marketing research. International Marketing Review, 18, 30-44. 
Unger, J.B., Cruz, T., Shakib, S., Mock, J., Shields, A., Baezconde-Garbanati, L., Palmer, P., Cruz, J.D., Edsall, E.W., Gritz, E.R., Glynn, T., \& Johnson, A. (2003). Exploring the cultural context of tobacco use: A transdisciplinary framework. Nicotine \& Tobacco Research, 5, S101-117.

Vassallo, M., Saba A., Arvola, A., Dean, M., Messina, F., Winkelmann, M., Claupein,E., Lahteenmaki, L., \& Shepherd, R. (2009). Willingness to use functional breads: Applying the Health Belief Model across four European countries. Appetite, 52, 452-460.

Walsh, G., Shiu, E., \& Hassan, L.M. (2014). Cross-national advertising and behavioral intentions: A multilevel analysis. Journal of International Marketing, 22, 77-98.

Wolburg, J.M. (2006). College students' responses to antismoking messages: Denial, defiance, and other boomerang effects. Journal of Consumer Affairs, 40, 294-323. 


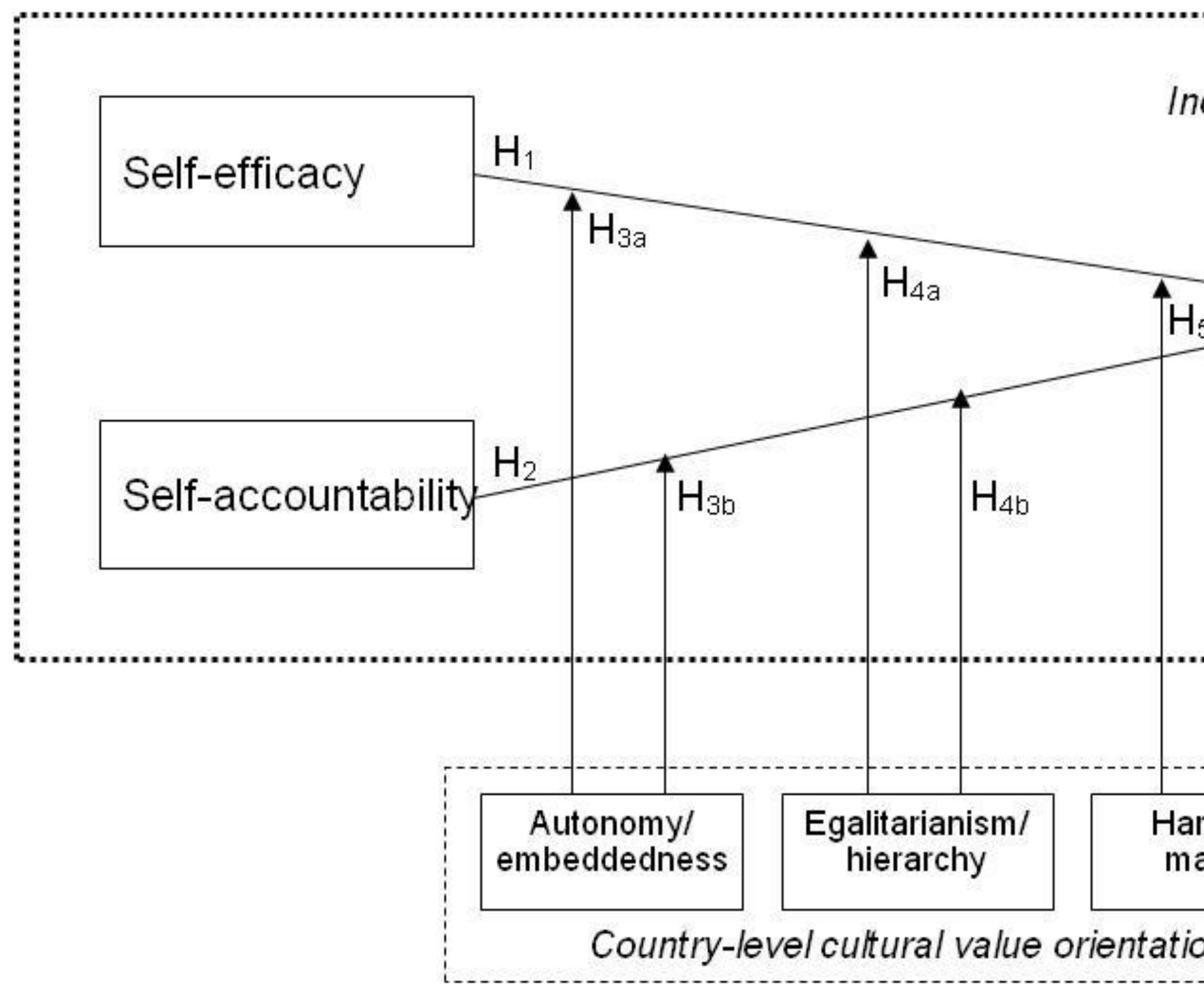

Fig. 1. Cross-level conceptual model. 


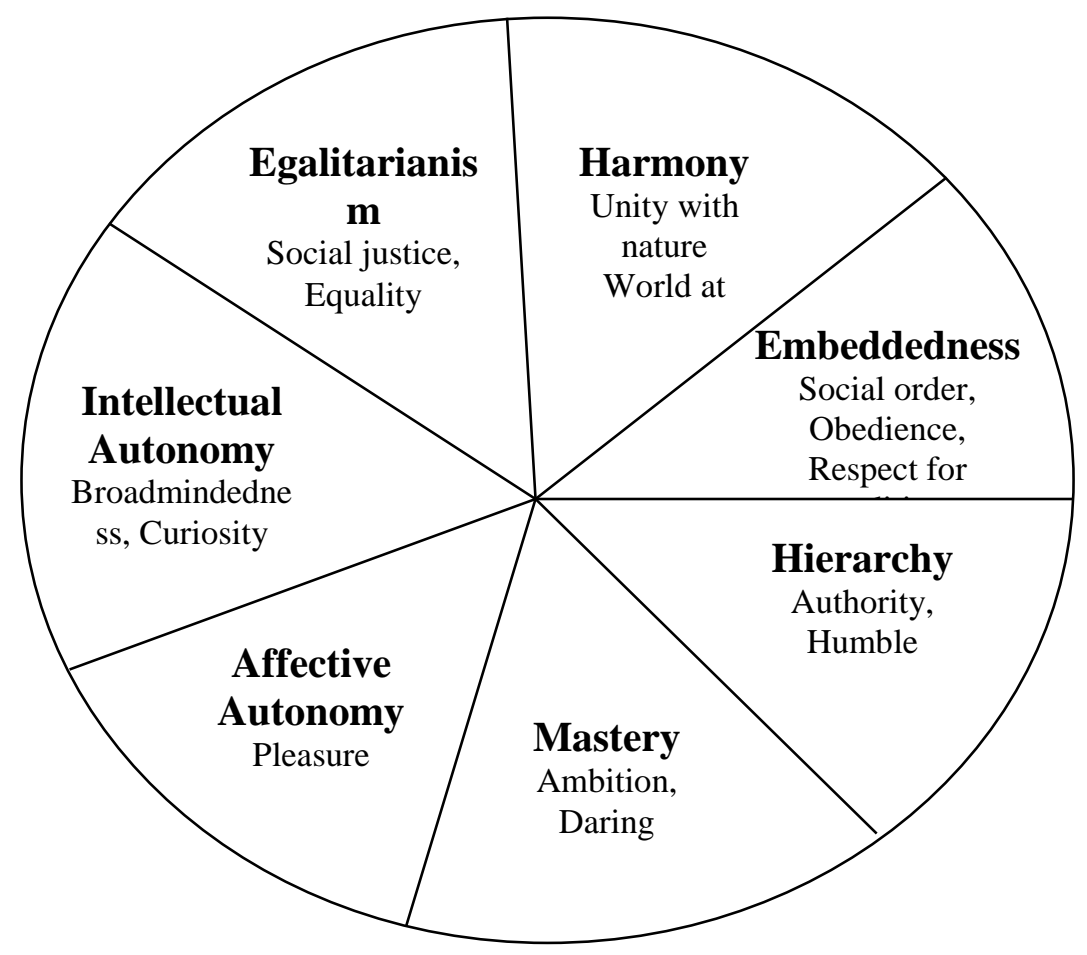

Fig. 2. Structural relations among the seven value orientations (Schwartz, 2006). 

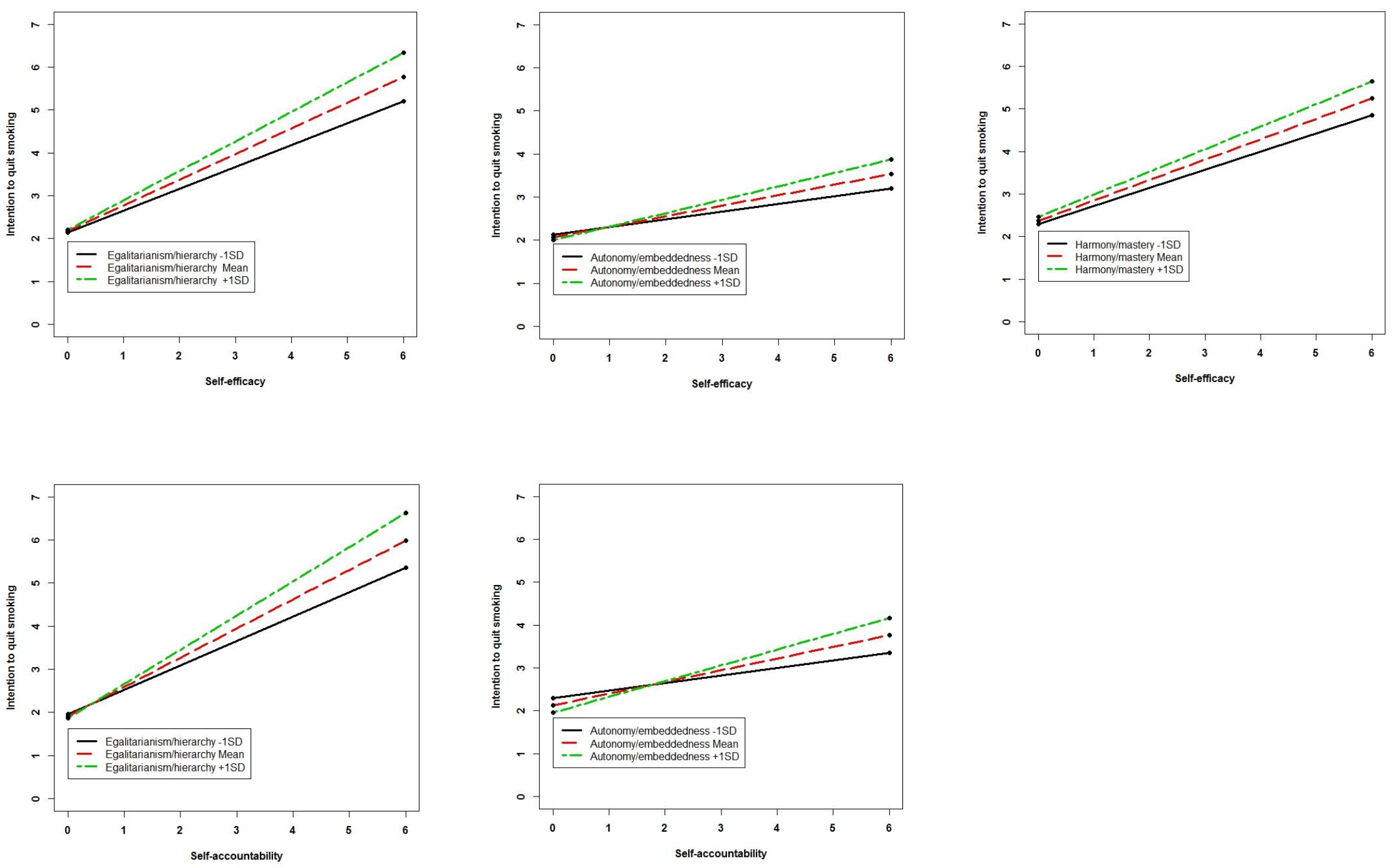

Fig. 3. Interaction plot for cross-level moderating effects 
Table 1

HLM slope-as-outcome model predicting intention to quit smoking

\begin{tabular}{|c|c|c|c|c|c|c|}
\hline & \multicolumn{2}{|l|}{ Model 1} & \multicolumn{2}{|l|}{ Model 2} & \multicolumn{2}{|l|}{ Model 3} \\
\hline & $B(S E)$ & $t$ & $B(S E)$ & $t$ & $B(S E)$ & $t$ \\
\hline \multicolumn{7}{|l|}{ Individual-level effects } \\
\hline Intercept & $2.05(.07)$ & $29.70 * * *$ & $2.05(.07)$ & $28.13 * * *$ & $2.05(.07)$ & $27.78 * * *$ \\
\hline Self-efficacy & $.27(.03)$ & $9.76 * * *$ & $.27(.03)$ & $10.43^{* * *}$ & $.26(.03)$ & $9.42 * * *$ \\
\hline Self-accountability & $.32(.04)$ & $8.79 * * *$ & $.33(.04)$ & $8.83 * * *$ & $.32(.04)$ & $7.97 * * *$ \\
\hline \multicolumn{7}{|l|}{ Schwartz-Country-level effects } \\
\hline Autonomy/embeddedness & $-.43(.21)$ & $-2.04 *$ & & & & \\
\hline Autonomy/embeddedness $\times$ self-efficacy & $.15(.08)$ & $1.81 *$ & & & & \\
\hline Autonomy/embeddedness $\times$ self-accountability & $.21(.10)$ & $2.04 *$ & & & & \\
\hline Egalitarianism/hierarchy & & & $-.10(.15)$ & -.66 & & \\
\hline Egalitarianism/hierarchy $\times$ self-efficacy & & & $.16(.05)$ & $3.18 * * *$ & & \\
\hline Egalitarianism/hierarchy $\times$ self-accountability & & & $.14(.07)$ & $2.10 * *$ & & \\
\hline Harmony/mastery & & & & & $.26(.16)$ & 1.60 \\
\hline Harmony/mastery $\times$ self-efficacy & & & & & $.17(.08)$ & $2.21 *$ \\
\hline Harmony/mastery $\times$ self-accountability & & & & & $.00(.08)$ & .00 \\
\hline $\mathrm{R}^{2}$ Self-efficacy slope & .10 & & .23 & & .09 & \\
\hline $\mathrm{R}^{2}$ Self-accountability slope & .20 & & .11 & & - & \\
\hline
\end{tabular}

Notes: B, unstandardized beta coefficient; SE, standard error; $* p<.10 ; * * p<.05 ; * * * p<.01$ (two-tailed). 